\title{
PCREB in the Neonate Rat Olfactory Bulb Is Selectively and Transiently Increased by Odor Preference-Conditioned Training
}

\author{
John H. McLean, ${ }^{1,3}$ Carolyn W. Harley, ${ }^{2}$ Andrea Darby-King, ${ }^{1}$ and Qi Yuan ${ }^{1}$ \\ ${ }^{1}$ Division of Basic Medical Sciences and ${ }^{2}$ Department of Psychology, Memorial University of Newfoundland, St. John's, \\ Newfoundland, Canada A1B 3V6
}

\begin{abstract}
Early olfactory preference learning in rat pups occurs when novel odors are paired with tactile stimulation, for example stroking. CAMP-triggered phosphorylation of cAMP response element binding protein (pCREB) has been implicated as a mediator of learning and memory changes in various animals (Frank and Greenberg 1994). In the present study we investigate whether CREB is phosphorylated in response to conditioned olfactory training as might be predicted given the proposed role of the phosphorylated protein in learning.

On postnatal day 6 , pups were trained for 10 min using a standard conditioned olfactory learning paradigm in which a conditioned stimulus, Odor, was either used alone or paired with an unconditioned stimulus, Stroking (using a fine brush to stroke the pup). In some instances stroking only was used. The pups were sacrificed at $0,10,30$, or 60 min after the training. Using Western blot analysis, we observed that the majority of olfactory bulbs in conditioned pups (Odor + Stroking) had a greater increase in pCREB activation at $10 \mathrm{~min}$ after training than pups given nonlearning training (Odor only or Stroking only). The phosphorylated protein levels were low at 0 min and at $60 \mathrm{~min}$ after training. This is in keeping with the slightly delayed and short-lived activation period for this protein.

The localization of PCREB increases within the olfactory bulb as seen by
\end{abstract}

${ }^{3}$ Corresponding author.

E-MAIL mclean@morgan.ucs.mun.ca; FAX (709) 737-7010. immunocytochemistry. Naive pups were not exposed to odor or training. There was a significantly higher level of label in mitral cell nuclei within the dorsolateral quadrant of the bulb of pups undergoing odor-stroke pairing. No significant differences were observed among nonlearning groups (Naive, Odor only, or Stroking only) or among any training groups in the granule or periglomerular cells of the dorsolateral region. The localized changes in the nuclear protein are consistent with studies showing localized changes in the bulb in response to a learned familiar odor. The present study demonstrates that selective increases in pCREB occur as an early step following pairing procedures that normally lead to the development of long-term olfactory memories in rat pups. These results support the hypothesized link between pCREB and memory formation.

\section{Introduction}

The recently hypothesized role for cAMP response element binding protein (CREB) as a universal modulator of processes required for memory formation is supported by a set of empirical studies in which CREB levels are manipulated. Enhancement or attenuation of CREB levels, respectively, enhance or attenuate aversively motivated, and more recently, appetitively motivated, long-term memories (Silva et al. 1998). In particular, CREB levels have been shown to critically influence memories for olfactory avoidance conditioning in fruit flies (Yin et al. 1995; Tully 1996), defensive withdrawal conditioning in Aplysia (Abel and Kandel 1998; Bartsch et al. 1998; Michael et al. 1998) and avoidance conditioning, spatial escape learning, and social preference learning in rodents (Silva et al. 1998). CREB has also been shown to be phos-

LEARNING \& MEMORY 6:608-618 @ 1999 by Cold Spring Harbor Laboratory Press ISSN1072-0502/99 \$5.00

$$
\begin{array}{lllllllllllllll}
L & E & A & R & N & I & N & G & \underset{608}{\mathbf{Q}} & M & E & M & O & R & Y
\end{array}
$$


phorylated in songbirds which hear a song from their own species (Sakaguchi et al. 1999).

The pathway by which CREB is hypothesized to be recruited during learning has been outlined by Frank and Greenberg (1994). Exposure to a neurotransmitter leads to the generation of increased amounts of CAMP, allowing the catalytic subunit of protein kinase A to translocate to the nucleus. In the nucleus, protein kinase A phosphorylates CREB at the Ser-133 site. Phosphorylated CREB (pCREB), in turn, can activate the transcription of immediateearly genes. The protein products of the immediate-early genes are transcription factors that go on to activate the transcription of late response genes such as brain-derived neurotrophic factor (Tao et al. 1998). It is these late response genes that are likely to be responsible for changes in neurotransmitters, neurotrophins/receptors, adhesion molecules, and cytoskeletal protein-the necessary components of long-term plasticity (learning) changes.

From this sequence it follows that if CREB has a critical role in initiating the genomic transcription underlying long-term memory, then CREB phosphorylation should be an early step in the development of long-term memories. Translocation of a protein kinase A subunit to the nucleus of Aplysia sensory neurons following serotonin application has been demonstrated as critical for serotonin facilitation (Abel and Kandel 1998), implying that an increase in CREB phosphorylation occurs in this form of plasticity. In mammalian studies, increased levels of pCREB have also been demonstrated to accompany increases in synaptic strength in several model systems (Bito et al. 1996; Deisseroth et al. 1996, 1998; Impey et al. 1996; Moore et al. 1996). However, no mammalian studies have demonstrated CREB phosphorylation that is linked specifically to associative learning procedures.

In rat neocortex, the level of pCREB is normally increased significantly during the waking phase of the daily cycle. This increase depends on intact locus coeruleus innervation (Cirelli et al. 1996). A critical role for noradrenergic locus coeruleus input in supporting CREB phosphorylation is consistent with the role of cAMP and the catalytic unit of protein kinase A in mediating phosphorylation. Calcium can also mediate CREB phosphorylation, but the failure to see normal pCREB elevation in the adult brain following noradrenergic lesions suggests calcium may not be sufficient.

In the present study we measure the occur- rence of CREB phosphorylation in an olfactory learning paradigm in neonate rats in which noradrenergic input from the locus coeruleus has been critically implicated. Stroking of a pup is known to activate cells of the noradrenergic locus coeruleus (Nakamura et al. 1987) and an olfactory preference is conditioned in neonate rats by pairing stroking with a novel odor (Sullivan and Leon $1986 \mathrm{~b}, 1987)$. The acquisition of a preference for the novel odor requires activation of $\beta$ adrenoceptors in the rat olfactory bulb (Sullivan et al. 1989a). Thus, the odor conditioning is dependent on a noradrenergic unconditioned stimulus signal coupled to cAMP increases which could initiate CREB phosphorylation through translocation of the catalytic subunit of protein kinase A. The glutamatergic odor input (Berkowicz et al. 1994; Ennis et al. 1996) occurring simultaneously with $\beta$-adrenoceptor activation could further heighten CREB phosphorylation through the synergistic actions of calcium on $\mathrm{Ca}^{2+}$-dependent kinases, which also induce CREB phosphorylation (Deisseroth et al. 1996; Tao et al. 1998). CREB phosphorylation, if sufficiently sustained, should activate the genomic transcription necessary to support the long-term odor preference memory. To test the hypothesis that CREB phosphorylation is selectively triggered by odor preference acquisition, pups were either given Odor + Stroking pairings, which reliably lead to odor preferences in tests $24 \mathrm{hr}$ later, or Odor only or Stroking only, which does not lead to odor preference in subsequent testing. Pups were sacrificed at several intervals following training and assessed for pCREB levels by Western blot. Neuroanatomical distribution of PCREB was also visualized using immunocytochemistry. We found that pCREB protein was increased transiently in the olfactory bulb after olfactory preference conditioning and that the pCREB increases occurred in a region associated previously with processing of the preferred odor. These results support a selective role for CREB phosphorylation as an initial step in mammalian learning.

\section{Materials and Methods}

\section{ANIMALS}

Sprague-Dawley rats were used in this study, which was approved by the Institutional Animal Care Committee of Memorial University of Newfoundland. Litters were culled to 12 pups on postnatal day (PND) 1, whereas the day of birth is con-

$$
\begin{array}{lllllllllllllll} 
& E & A & R & N & I & N & G & \underset{609}{\bigotimes} & M & E & M & O & R & Y
\end{array}
$$


sidered PND0. A total of 27 pups from 10 litters (for Western blot analysis) and 24 pups from 6 litters (for immunocytochemistry) were used in this study. These numbers were the minimum possible to provide statistically significant results. A maximum of one male and female pup from each litter was used for each training group described below.

\section{CONDITIONING EXPERIMENTS AND SACRIFICE}

Rat pups (PND6) were subjected to conditions that had been shown previously (McLean et al. 1993; Langdon et al. 1997; Price et al. 1998) to produce conditioned olfactory learning (Odor + Stroking) or not (Naive, Odor only, Stroking only). To this end, the pups were placed on normal (Stoking only) or peppermint-scented bedding ( $250 \mu \mathrm{l} /$ $300 \mathrm{ml}$ of bedding) and stroked vigorously on the hind region using a paintbrush every other $30 \mathrm{sec}$ for $30 \mathrm{sec}$ (Odor + Stroking) or not (Odor only) over a $10 \mathrm{~min}$ period. The pups in the present experiment were subjected to training procedures but were not tested for recall because we wished to examine the role of PCREB specifically in the acquisition of olfactory learning. In previous studies, we (McLean et al. 1993, 1996; Langdon et al. 1997; Price et al. 1998), as well as others (Sullivan and Leon 1986a, 1987; Sullivan et al. 1989a, 1991), have shown that pups subjected to the different training procedures show predictable behavioral outcomes.

For Western blot analysis after the various training conditions (Odor + Stroking, Odor only, Stroking only, or Naive), the pups were sacrificed by decapitation at various intervals. The post-training time giving the strongest pCREB induction in Western blot analysis was used as the sacrifice time in subsequent experiments. For immunocytochemical analysis of pCREB, pups were sacrificed 10 min after training (Odor + Stroking, Odor only, Stroking only, or Naive) by overdose with sodium pentobarbital and perfused transcardially with fixative as described previously (McLean et al. 1993).

\section{PROTEIN PREPARATION AND DETERMINATION FOR WESTERN BLOTS}

After sacrifice, both olfactory bulbs were immediately frozen on dry ice and subsequently stored in microcentrifuge tubes at $-70^{\circ} \mathrm{C}$ until use. Ice-cold lysis buffer containing $0.1 \%$ SDS, 1\%
NP-40, $20 \mathrm{~mm}$ Tris, 10\% glycine, and $1.37 \mathrm{~mm}$ sodium chloride with $1 \mu \mathrm{g} / \mathrm{ml}$ leupeptin, $2 \mathrm{~mm}$ PMSF, 8.9 $\mathrm{U} / \mathrm{ml}$ aprotinin, and $1 \mathrm{~mm}$ sodium orthovanadate was added to each tube and each pair of bulbs was then ground using a homogenizer. The homogenate was left on ice for $30 \mathrm{~min}$ and then centrifuged at $13,000 \mathrm{rpm}$ for $15 \mathrm{~min}$ at $4^{\circ} \mathrm{C}$. The clear lysate containing the proteins of interest was stored in $50-\mu \mathrm{l}$ aliquots at $-70^{\circ} \mathrm{C}$. The protein concentration of each pair of olfactory bulbs was determined separately using a Pierce BCA Protein Assay kit.

\section{WESTERN BLOTTING}

Samples were prepared in $4 \mu \mathrm{l}$ of $5 \times$ sample buffer $(0.25$ м Tris-HCl, 10\% SDS, 50\% glycerol, $0.025 \%$ bromophenol blue, and $0.5 \mathrm{~m}$ dithiothreitol added just prior to use) plus sufficient sample and water to constitute $20 \mu \mathrm{l}$ of sample per well. Positive controls using forskolin-treated PC12 cells showed the appropriate band for pCREB. Samples and positive controls were boiled for $5 \mathrm{~min}$ and placed on ice until use. Equal weights of protein $(100 \mu \mathrm{g})$ from each sample were loaded into a lane. Proteins were separated on the basis of gel mobility using SDS-PAGE. Color-coded molecular weight standards (Bio-Rad) were loaded into a separate lane for each blot. The gel-running buffer was a solution containing $25 \mathrm{~mm}$ Tris, $250 \mathrm{~mm}$ glycine, and $3.5 \mathrm{~mm}$ SDS at $\mathrm{pH} 8.3$. Once proteins were loaded into one of 10 lanes, each gel apparatus was attached to a Bio-Rad power supply set to $100 \mathrm{mV}$.

The protein was then transferred at $4^{\circ} \mathrm{C}$ from the gel to nitrocellulose paper (Hybond ECL, Amersham) using a Bio-Rad power supply set to $0.2 \mathrm{~A}$ for $45 \mathrm{~min}$. The transfer solution contained $25 \mathrm{~mm}$ Tris, $192 \mathrm{~mm}$ glycine, and 20\% methanol. After the transfer, the nitrocellulose blots were processed for detection of pCREB or placed in Ponceau $S$ to visualize the total amount of protein transferred. Ponceau S was used on every blot (either after protein transfer or immunoblot) to determine if equal amounts of protein were loaded for comparisons.

The blots were rinsed $3 \times 5$ min in PBS with $0.05 \%$ Tween 20 (PBST) and then immersed in 5\% milk in PBS for $1 \mathrm{hr}$. Following $3 \times 5 \mathrm{~min}$ rinses in PBST, the blots were immersed in a polyclonal antibody to pCREB (1/1500 dilution, Upstate Biotechnology) with PBST overnight on a shaker at $4^{\circ} \mathrm{C}$. Following further washes in PBST and incubation (1 hr) in anti-rabbit IgG-horseradish peroxi-

$$
\begin{array}{lllllllllllllll} 
& E & A & R & N & I & N & G & \begin{array}{l}
\boldsymbol{Q} \\
610
\end{array} & M & E & M & O & R & Y
\end{array}
$$


dase, the blot was rinsed in PBST and visualized using enhanced chemiluminescence (Amersham).

\section{IMMUNOCYTOCHEMISTRY}

Standard immunocytochemical methods were used as described previously (McLean et al. 1993). In brief, $30-\mu \mathrm{m}$ frozen coronal sections through the bulb were cut and mounted on subbed slides (all sections were kept). The primary pCREB antibody was diluted $1 / 1500$ in PBS containing $0.2 \%$ Triton $\mathrm{X}-100$ and $2 \%$ normal goat serum. Following washes as described previously (McLean et al. 1993), the sections were incubated in biotinylated secondary antibody (Vectastain Elite) and then in a $0.05 \%$ solution of diaminobenzidine with $0.01 \%$ $\mathrm{H}_{2} \mathrm{O}_{2}$.

\section{ANALYSIS OF WESTERN BLOTS}

\section{AND IMMUNOCYTOCHEMICAL SECTIONS}

Only those blots that showed equal protein levels for paired bulbs were analyzed subsequently. The average optical density (avg = integrated density value/area) of Western blots was determined using ChemiImager (Alpha Innotech Corp.). The integrated density value is the sum of all pixel values on a scale from 0 (white) to 255 (black) in the defined region and the area is the size in pixels of that defined region. The background integrated density was subtracted automatically from each blot area. The average optical densities were analyzed using a one-way repeated measures ANOVA. Tissues that were processed in the same Western blot run were grouped together. Using these criteria the analysis included seven triple sets (Odor + Stroking versus Odor only versus Stoking only). Additionally, three double sets (Odor + Stroking versus Odor only) were analyzed but could not be included in the repeated measures ANOVA because of the statistics criteria. Post hoc comparisons of the triple sets were made using the Newman-Keuls test.

For immunocytochemisty, the sections were analyzed systematically such that every third section through the bulb was examined. Image analysis (Bioquant, R\&M Biometrics, Inc.) was performed by tracing the region/cell layer of interest. Labeled cells were then captured digitally using a background subtraction and threshold method to eliminate any uneven lighting conditions. The percent area reaching threshold in the region of interest was determined for each olfactory bulb. In ad- dition, the number of cells reaching threshold were counted in the mitral cell layer. Threshold refers to pixels (which are converted to area) that fall within a given brightness level assigned to a gray level scale from the object of interest and provides a systematic and reliable means of identifying labeled cells. To assure objectivity, the slides were coded so that the person analyzing each section was unaware of the training procedure. The data were analyzed statistically by one-way ANOVA and the Newman-Keuls post hoc test.

\section{Results}

\section{WESTERN BLOT ANALYSIS}

IDENTITY AND SENSITIVITY OF THE PCREB BAND

In Western blots, PC12 cells treated with forskolin (known to increase pCREB levels) showed a band at $43 \mathrm{kD}$ that was substantially more intense than that observed in untreated PC12 cells (Fig. 1). This observation demonstrates the specificity of the antibody for pCREB and confirms that the technique is sensitive to changes in pCREB. Furthermore, a band located at the same molecular mass (43 kD) was observed in the olfactory bulbs of PND6 pups (Fig. 1).

TIME COURSE OF PCREB EXPRESSION

Immediately after training or in naive pups, pCREB levels were very low (Fig. 2). Levels of pCREB were highest 10 min after training and began to subside at $30 \mathrm{~min}$ and $60 \mathrm{~min}$ (Fig. 2).

PCREB PROTEIN LEVELS IN OLFACTORY BULBS OF CONDITIONED VS. NONCONDITIONED PUPS

The olfactory bulbs of pups that were trained to learn (Odor + Stroking) generally showed in-

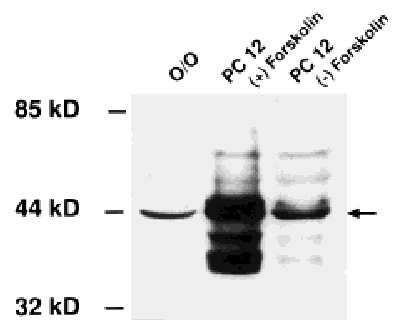

Figure 1: Western blot showing the specificity of the pCREB antibody and its sensitivity in detecting changes in pCREB levels. $(\mathrm{O} / \mathrm{O})$ olfactory bulb of a pup given Odor only. Forskolin, when administered to PC12 cells [PC 12 (+) Forskolin], induces pCREB expression as indicated by the bands at the arrow.

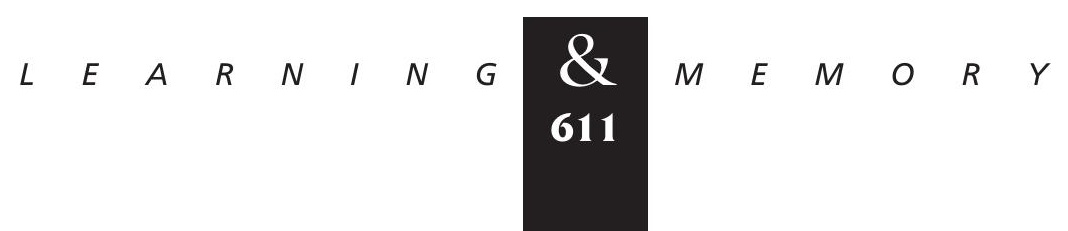




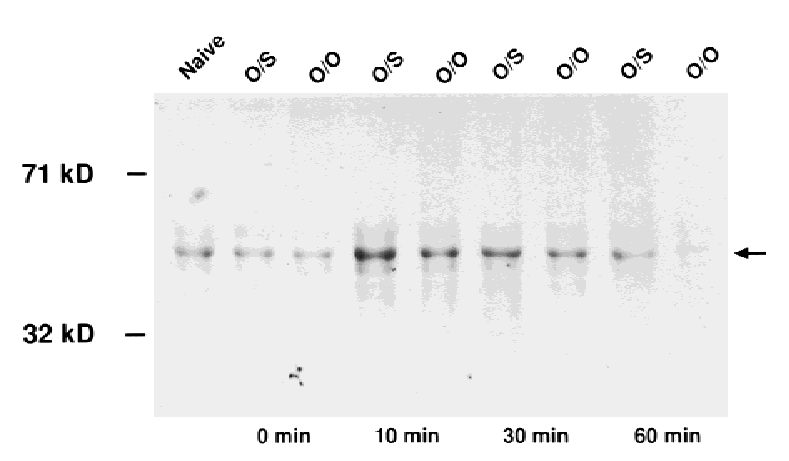

Figure 2: Western blot showing the change in PCREB expression (arrow) over time following conditioned olfactory training. $(\mathrm{O} / \mathrm{S})$ Odor + Stroking (learning); $(\mathrm{O} / \mathrm{O})$ Odor only; (Naive) not exposed to peppermint odor or stroking. Note that the most intense activation is $\sim 10$ min after training.

creased levels of pCREB 10 min after training (Figs. 3 and 4) compared to pups subjected to a non olfactory learning situation (i.e., Odor only or Stroking only). The one-way ANOVA revealed a significant effect of groups $\left(F_{2,12}=4.6, P=0.033\right)$. In the Newman-Keuls test the Odor + Stroking pairing group (average density $=65.3$ ) was significantly higher $(P<0.05)$ than either the Stroking only (average density $=44.0$ ) or Odor only (average density $=44.9)$ groups, which did not differ from each other. In the three additional pairs of Odor + Stroking (average density $=67.3$ ) and Odor only (average density $=49.9$ ) pups, the results were similar to those for the larger group. Although the odor conditioned pups showed significantly greater pCREB (Fig. 4) 10 min after the training period compared to the nonlearning situations, not all bulbs exhibited the increase. When data from samples run on the same blots were com-

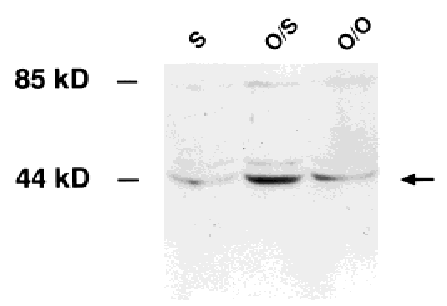

Figure 3: Representative Western blot showing pCREB levels in the olfactory bulbs of pups subjected to the conditioned learning of odor paired with stroking $(\mathrm{O} / \mathrm{S})$ or to non learning training [Odor only $(\mathrm{O} / \mathrm{O})$ or Stroking only $(\mathrm{S})]$. The arrow indicates the pCREB protein band from both olfactory bulbs of one animal for each training condition.

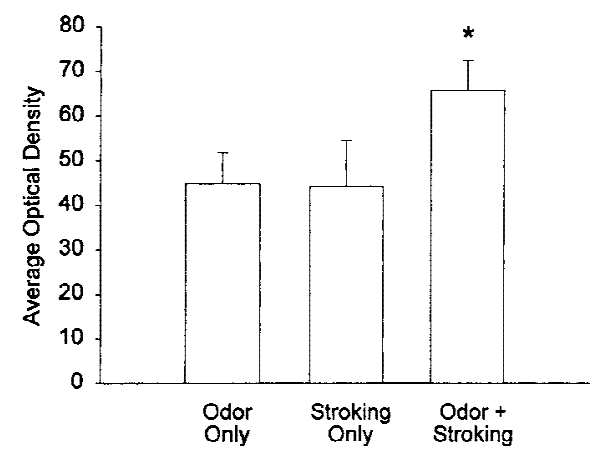

Figure 4: The average optical density (mean \pm S.E.M.) of pCREB Western blot analysis in the olfactory bulbs of pups trained to Odor only, Stroking only, or Odor + Stroking (conditioned learning). $(*) \quad P<0.05$. Each treatment included seven pups.

pared, Odor + stroking levels were greater than Odor only in 9 out of 10 comparisons while the Odor + Stroking conditioned pups showed increased pCREB levels in 6 out of 7 comparisons with Stroking only pups.

\section{IMMUNOCYTOCHEMISTRY}

There were many cells labelled in the olfactory bulb of all animals examined, but the mitral cells were significant in label intensity. The dorsolateral quadrant, in particular, appeared to have increased labeled cells and was, thus, analyzed in some detail (Fig. 5). In addition, the ventromedial quadrant, which appeared to have few mitral cells labeled, was analyzed in detail. Quantitative analysis of nuclei areas reaching threshold revealed a significantly higher level of pCREB label within the mitral cell layer in the dorsolateral quadrant of pups subjected to the learning (Odor + Stroking) paradigm compared to pups which received no training ( Naive), Odor only, or Stroking only. The ventromedial quadrant showed less density of mitral cell label and no significant difference in label among learning (Odor + Stroking) and nonlearning (Naive, Stroking only, Odor only) conditions (Fig. 6). Neither the periglomerular nor granule cell populations within those same regions showed any significant differences among training groups (Fig. 6). The number of mitral cells reaching threshold in the dorsolateral quadrant was also analyzed and, similar to the analysis of threshold areas, one way ANOVA showed significance $\left(F_{3,20}=3.20, P=\right.$ $0.045)$. The post hoc Newman-Keuls test revealed that the density of cells in the Odor + Stroking

$$
\begin{array}{llllllllllllllll} 
& E & A & R & N & I & N & G & \boldsymbol{Q} \\
\mathbf{6 1 2} & M & E & M & O & R & Y
\end{array}
$$



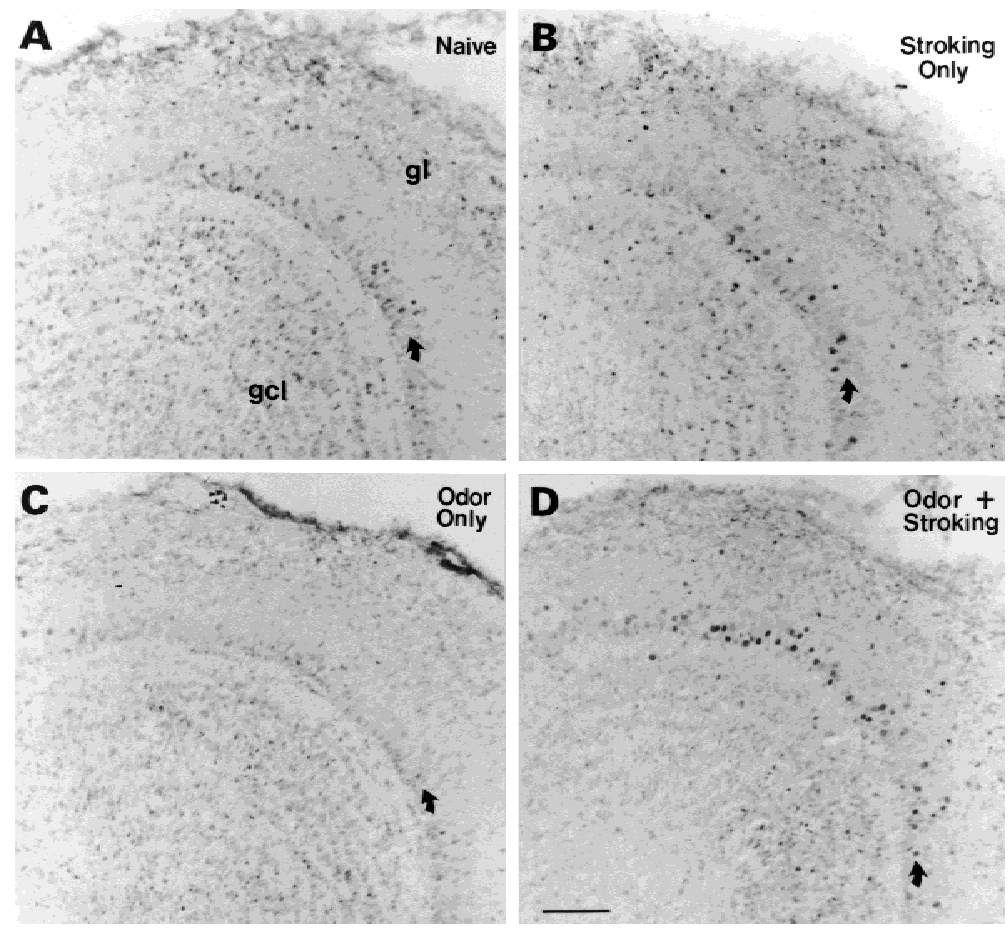

Figure 5: Representative immunocytochemical localization of PCREB in the dorsolateral quadrant of the bulb in PND6 pups sacrificed $10 \mathrm{~min}$ after no training, i.e., Naive $(A)$ or training by Stroking only $(B)$, Odor only $(C)$, or Odor + Stroking $(D)$. The pCREB label was observed in the nucleus of several cell types but especially in mitral cells of pups trained by Odor + Stroking. A-D are at the same magnification as the bar in $D(100$ $\mu \mathrm{m})$. group $\left(\operatorname{avg}=2.0\right.$ cells $\left./ 10,000 \mu^{2}\right)$ was significantly different from the Stroking only group (avg $=1.2$ cells $\left./ 10,000 \mu^{2}, P<0.05\right)$ and Naive group (avg $=1.2$ cells $\left./ 10,000 \mu^{2}, P<0.05\right)$ while the Odor only group $\left(\operatorname{avg}=1.1\right.$ cells $\left./ 10,000 \mu \mathrm{m}^{2}\right)$ was not significant.

\section{Discussion}

The significantly greater increase in PCREB in the olfactory bulb of rat pups undergoing a training procedure known to produce a conditioned preference for peppermint odor $24 \mathrm{hr}$ later (McLean et al. 1993; Langdon et al. 1997; Price et al. 1998) supports the hypothesis that CREB is a universal memory molecule implicated in the initiation of long-term memories. Neither Odor alone, which can increase c-fos expression in similar regions of the olfactory bulb (Guthrie and Gall 1995a,b; Johnson et al. 1995), nor Stroking alone, which is known to activate noradrenergic neurons involved in modulating pCREB levels (Cirelli et al. 1996), was able to produce a comparable increase in CREB phosphorylation. In initial experiments we also observed that the olfactory bulbs of Naive pups exhibited relatively low levels of pCREB (Fig. 2). Low levels of pCREB were quantitated by immunocytochemistry in the bulbs of Naive pups, an observation which was in keeping with the qualitative observations in Western blots. Thus, baseline levels of pCREB were observed in Naive pups as well as pups given nonlearning training. The qualitative and quantitative data suggest that pCREB is increased only when pups are trained by conditioning. This is consistent with a model in which both a calcium signal initiated by the odor input (Bozza and Kauer 1998) and a cAMP signal initiated by norepinephrine are required synergistically to elevate significantly pCREB levels. While the selectivity of the pCREB increase for the pairing condition supports a special role of the CREB promoter in associative learning, future investigations should compare forward (Odor + Stroking) and backward (Stroking followed by Odor, nonlearning) pairing. A demonstration of an effect of pairing order, which is known to affect memory formation in this paradigm (McLean et al. 1996; Sullivan and Hall 1988; Sullivan et al. 1991; Sullivan et al. 1989b; Wilson and Sullivan 1991), would provide the strongest test of the claim for a unique association between pCREB increases and associative memory formation.

\section{TEMPORAL AND SPATIAL CHARACTERISTICS OF PCREB INCREASES}

As predicted by the Frank and Greenberg

$$
\begin{array}{lllllllllllllll}
L & E & A & R & N & I & N & G & \mathbf{Q} & M & E & M & O & R & Y \\
\mathbf{6 1 3} & & & & & & &
\end{array}
$$




\section{McLean et al.}

Figure 6: Graph showing the density of pCREB immunoreactive cells ( $\%$ area reaching threshold) in various regions of the olfactory bulb. Notice that a significantly higher level of pCREB label was observed in the dorsolateral quadrant mitral cells in animals that were conditioned to the peppermint odor (Odor + Stroking). $\left({ }^{*}\right) P<0.05 . N=6$ for each treatment.
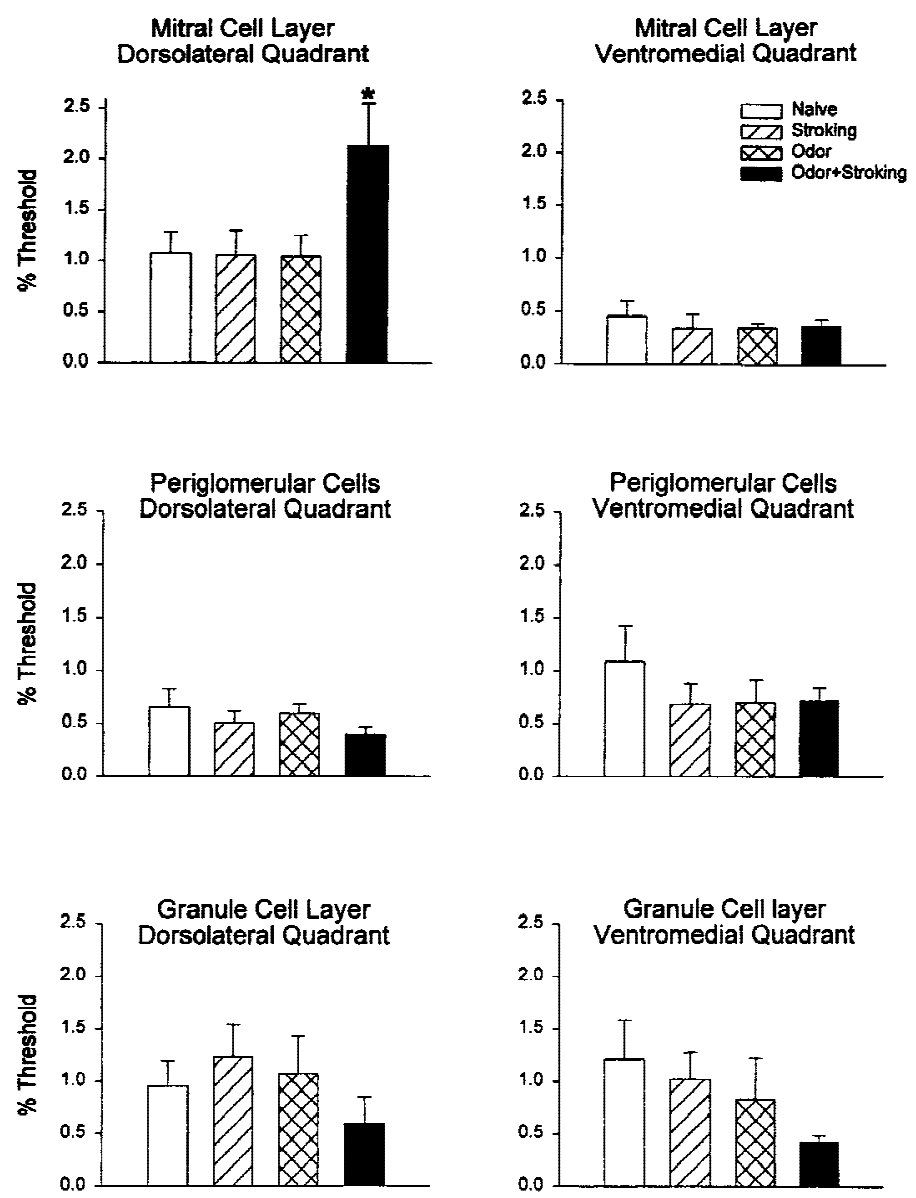

model (1994) changes in pCREB were transient with increases peaking at $10 \mathrm{~min}$ after the session and returning near the control range at $60 \mathrm{~min}$ after the session. This pattern is similar to previously reported temporal patterns of pCREB activation (Bito et al. 1996; Impey et al. 1996; Moore et al. 1996; Matthies et al. 1997; Deisseroth et al. 1998) and is consistent with the rapid and transient time course required for the catalytic $\mathrm{C}$ subunit of protein kinase A to translocate to the nucleus after adenylate cyclase/cAMP activation (Nigg et al. 1985).

Given the overall increase in PCREB protein (Western blots) in the bulb associated with learning (Odor + Stroking), one might have predicted substantial increases in pCREB observed by immunocytochemistry. While we did observe regional and cell specific increases, the overall number of pCREB cells localized in all populations in the bulb did not appear to be dramatically increased in the learning (Odor + Stroking) situation. A possible explanation for this apparent discrepancy may be that large mitral cells produce a large amount of
pCREB, which may not be reflected by cellular localization with immunocytochemistry but is detectable by Western blot analysis.

In the present study, the localization of the pairing-associated pCREB changes in the dorsolateral olfactory bulb overlaps with the midlateral portion of the bulb shown to be associated with increased 2-deoxyglucose activity in rats that have been conditioned to the same peppermint odor (Coopersmith and Leon 1986; Sullivan and Leon 1986a, 1987; Sullivan et al. 1988; Woo et al. 1987). The localization of pCREB in the dorsolateral region correlates very well to c-fos mRNA expression in response to peppermint odor (Guthrie et al. 1993), which was shown to activate periglomerular, mitral, and granule cells in adult rats and to the general region (midlateral) of c-fos activated by retrieval of a conditioned peppermint odor in older pups (Johnson et al. 1995). However, in retrieval studies, increases in fos-reactive cells have been associated selectively with the periglomerular region in response to peppermint odors (Guthrie et al. 1993; Johnson et al. 1995; Schwab 1996). Cell

$$
\begin{array}{lllllllllllllll}
L & E & A & R & N & I & N & G & \boldsymbol{Q} \\
\mathbf{6 1 4} & M & E & M & O & R & Y
\end{array}
$$


numbers in the periglomerular region (Coopersmith and Leon 1986; Woo and Leon 1987, 1991; Sullivan et al. 1990, 1991; Matsutani and Leon 1993; Johnson et al. 1995), the density of glial processes in the glomeruli (Matsutani and Leon 1993) and the area of the glomerular neuropil (Woo et al. 1987) are all increased in pups that have undergone 18 days of conditioning procedures. The results from the present study, however, highlight a role of mitral cell activation in the initial acquisition of conditioned preference to a novel odor. Whether such activation leads to alterations in mitral cell dendrites which might contribute to the later observations of increases in glomerular neuropil or periglomerular cells remains to be investigated. It will be important to assess more directly the relationship between odor input and pCREB activation during acquisition by measuring metabolic activation simultaneously using 2-deoxyglucose techniques and pCREB activation using immunoctytochemical techniques on sections from the same subjects.

The pCREB changes in the present study are widespread within the dorsolateral quadrant, a pattern consistent with encoding changes occurring throughout a neural network rather than at a few hot spots within the olfactory bulb. Both excitatory and inhibitory connections are likely to be altered during learning (Wilson and Sullivan 1990) so it may not be surprising to have widespread regional activation of CREB.

\section{MONOAMINE INTERACTIONS IN CONDITIONED} OLFACTORY LEARNING: POSSIBLE PCREB SYNERGY

Although noradrenergic input appears to act as the critical unconditioned stimulus for olfactory conditioned preference learning, we have found that serotonergic depletion of the olfactory bulb can prevent such learning. Our earlier work suggests that $5-\mathrm{HT}$ acting through $5-\mathrm{HT}_{2}$ receptors normally promotes noradrenergic-induced plasticity. Although sufficient $\beta$ adrenoceptor activation can overcome the requirement for $5-\mathrm{HT}_{2}$ input during olfactory preference learning (Langdon et al. 1997), an increase of $5-\mathrm{HT}_{2}$ stimulation can produce learning with a subthreshold noradrenergic stimulus (Price et al. 1998). 5- $\mathrm{HT}_{2}$ activation alone does not seem to produce learning. These results fit with the hypothesis that these two inputs may act synergistically on the same cells with respect to increasing cAMP. The $\beta 1$ adrenoceptor is coupled to a $G$ protein which, upon activation, stimulates adenyl cyclase induced cAMP production (De Blasi 1989). If cAMP-mediated long-term plasticity is the substrate for olfactory preference learning, as suggested by the present study, this would parallel the role of $\beta$ adrenoceptors and/or cAMP in the plasticity of the developing visual system (Kasamatsu 1983; Kasamatsu and Shirokawa 1985) and in learning-related plasticity in a variety of biological systems (Abrams et al. 1991; Levin et al. 1992; Frank and Greenberg 1994; Tully et al. 1994). Although 5-HT receptor activation does not by itself increase cAMP expression (Morin et al. 1992), which is consistent with our failure to induce learning with such activation alone, $5-\mathrm{HT}_{2}$ activation can act through the phosphotidyl inositol second messenger system to enhance the generation of intracellular cAMP by isoproterenol or adenylate cyclase (Rovescalli et al. 1993). It follows that serotonin in the olfactory bulb might act to promote or intensify the norepinephrine-induced cAMP unconditioned stimulus signal.

The present results suggest mitral cells may be the critical cellular substrate for such interaction. Other studies have shown that $5-\mathrm{HT}_{2 \mathrm{~A}}$ receptor mRNA (McLean et al. 1995) and protein (Hamada et al. 1998) are localized in mitral/tufted cells and, to a much lesser extent, in periglomerular and granule cells (Hamada et al. 1998). Less is known concerning the cellular localization of the $\beta$ adrenoceptors, but one study has shown that mitral cells and periglomerular cells express $\beta 2$ adrenoceptor mRNA in the neonate bulb (K.J. Ivins, E. Ibrahim, and $\mathrm{M}$. Leon, unpubl.). Thus, it is possible that both serotonergic and noradrenergic axons act on mitral cells and/or interneurons to induce learning by activating pCREB. It is less likely that both act on periglomerular cells because very few noradrenergic axons reach the periglomerular region (McLean and Shipley 1991; McLean et al. 1989). However, it should be noted that there is relatively dense $\beta$ adrenoceptor binding in the glomerular layer (Woo and Leon 1995a) and lesions of the locus coeruleus increase $\beta 2$ adrenoceptor density (Woo et al. 1996), whereas conditioned learning decreases $\beta 2$ adrenoceptor density in glomerular foci (Woo and Leon 1995b). It will be of interest to observe changes in mitral cell pCREB following olfactory conditioning procedure in pups with various levels of $5-\mathrm{HT}_{2}$ and $\beta$ adrenoceptor activation.

Interestingly, in one of the first reports of the necessary and sufficient role of 5-HT in producing long-term change in the Aplysia $5-\mathrm{HT}_{2}$ nervous sys-

$$
\begin{array}{lllllllllllllll}
L & E & A & R & N & I & N & G & \boldsymbol{Q} \\
\mathbf{6 1 5} & M & E & M & O & R & Y
\end{array}
$$


tem, Brunelli et al. (1976) suggested that the likely mammalian analog to Aplysia serotonin input would be norepinephrine. The involvement of CREB in long-term plasticity was first reported in cultured sensory and motor neurons of Aplysia exposed to a serotonergic signal. It now appears, as Brunelli et al. (1976) hypothesized, that norepinephrine functions in an analogous manner via CREB activation to induce a long-term memory in neonate rats.

\section{Acknowledgments}

This work was supported by the Medical Research Council of Canada (MT-14148).

The publication costs of this article were defrayed in part by payment of page charges. This article must therefore be hereby marked "advertisement" in accordance with 18 USC section 1734 solely to indicate this fact.

\section{References}

Abel, T. and E. Kandel. 1998. Positive and negative regulatory mechanisms that mediate long-term memory storage. Brain Res. Rev. 26: 360-378.

Abrams, T.W., K.A. Karl, and E.R. Kandel. 1991. Biochemical studies of stimulus convergence during classical conditioning in Aplysia: Dual regulation of adenylate cyclase by $\mathrm{Ca}^{2+} /$ calmodulin and transmitter. J. Neurosci. 11: 2655-2665.

Bartsch, D., A. Casadio, K.A. Karl, P. Serodio, and E.R. Kandel. 1998. CREB1 encodes a nuclear activator, a repressor, and a cytoplasmic modulator that form a regulatory unit critical for long-term facilitation. Cell 95: 211-223.

Berkowicz, D.A., P.Q. Trombley, and G.M. Shepherd. 1994. Evidence for glutamate as the olfactory receptor cell neurotransmitter. J. Neurophysiol. 71: 2557-2561.

Bito, H., K. Deisseroth, and R.W. Tsien. 1996. CREB phosphorylation and dephosphorylation: $\mathrm{A} \mathrm{Ca}^{2+}$ - and stimulus duration-dependent switch for hippocampal gene expression. Cell 87: 1203-1214.

Bozza, T.C. and J.S. Kauer. 1998. Odorant response properties of convergent olfactory receptor neurons. J. Neurosci. 18: 4560-4569.

Brunelli, M., V. Castellucci, and E.R. Kandel. 1976. Presynaptic facilitation as a mechanism for behavioral sensitization in Aplysia. Science 194: 1176-1180.

Cirelli, C., M. Pompeiano, and G. Tononi. 1996. Neuronal gene expression in the waking state: A role for the locus coeruleus. Science 274: 1211-1215.

Coopersmith, R. and M. Leon. 1986. Enhanced neural response by adult rats to odors experienced early in life. Brain Res. 371: 400-403.
De Blasi, A. 1989. Advances on beta-adrenergic receptors: Molecular structure and functional regulation. Am. J. Hypertens. 2: 252S-256S.

Deisseroth, K., H. Bito, and R.W. Tsien. 1996. Signaling from synapse to nucleus: Postsynaptic CREB phosphorylation during multiple forms of hippocampal synaptic plasticity. Neuron 16: 89-101.

Deisseroth, K., E.K. Heist, and R.W. Tsien. 1998. Translocation of calmodulin to the nucleus supports CREB phosphorylation in hippocampal neurons. Nature 392: 198-202.

Ennis, M., L.A. Zimmer, and M.T. Shipley. 1996. Olfactory nerve stimulation activates rat mitral cells via NMDA and non-NMDA receptors in vitro. NeuroReport 7: 989-992.

Frank, D.A. and M.E. Greenberg. 1994. CREB: A mediator of long-term memory from mollusks to mammals. Cell 79: 5-8.

Guthrie, K.M. and C.M. Gall. 1995a. Odors increase fos in olfactory bulb neurons including dopaminergic cells. NeuroReport 6: 2145-2149.

1995b. Functional mapping of odor-activated neurons in the olfactory bulb. Chem. Senses. 20: 271-282.

Guthrie, K.M., A.J. Anderson, M. Leon, and C. Gall. 1993. Odor-induced increases in c-fos mRNA expression reveal an anatomical "unit" for odor processing in olfactory bulb. Proc. Natl. Acad. Sci. 90: 3329-3333.

Hamada, S., K. Senzaki, K. Hamaguchi Hamada, K. Tabuchi, H. Yamamoto, T. Yamamoto, S. Yoshikawa, H. Okano, and N. Okado. 1998. Localization of 5-HT2A receptor in rat cerebral cortex and olfactory system revealed by immunohistochemistry using two antibodies raised in rabbit and chicken. Mol. Brain Res. 54: 199-211.

Impey, S., M. Mark, E.C. Villacres, S. Poser, C. Chavkin, and D.R. Storm. 1996. Induction of CRE-mediated gene expression by stimuli that generate long-lasting LTP in area CA1 of the hippocampus. Neuron 16: 973-982.

Johnson, B.A., C.C. Woo, H. Duong, V. Nguyen, and M. Leon. 1995. A learned odor evokes an enhanced fos-like glomerular response in the olfactory bulb of young rats. Brain Res. 699: 192-200.

Kasamatsu, T. 1983. Neuronal plasticity maintained by the central norepinephrine system in the cat visual cortex. Progr. Psychbiol. Physiol. Psychol. 10: 1-112.

Kasamatsu, T. and T. Shirokawa. 1985. Involvement of $\beta$-adrenoreceptors in the shift of ocular dominance after monocular deprivation. Exp. Brain Res. 59: 507-514.

Langdon, P.E., C.W. Harley, and J.H. McLean. 1997. Increased $\beta$ adrenoceptor activation overcomes conditioned olfactory learning deficits induced by serotonin depletion. Dev. Brain Res. 102: 291-293.

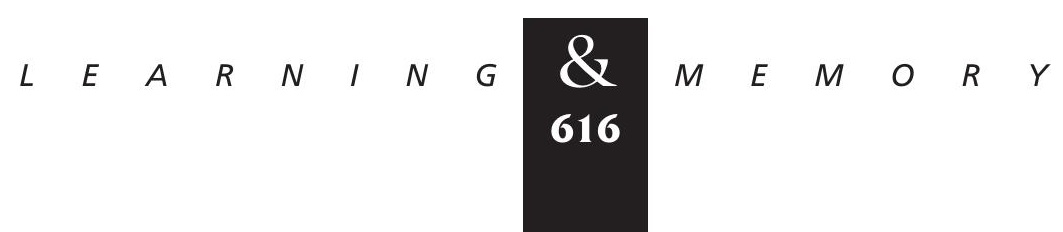


Levin, L.R., P. Han, P.M. Hwang, P.G. Feinstein, R.L. Davis, and R.R. Reed. 1992. The drosophila learning and memory gene rutabaga encodes a $\mathrm{Ca}^{2+} /$ calmodulin-responsive adenylyl cyclase. Cell 68: 479-489.

Matsutani, S. and M. Leon. 1993. Elaboration of glial cell processes in the rat olfactory bulb associated with early learning. Brain Res. 613: 317-320.

Matthies, H., S. Schulz, W. Thiemann, H. Siemer, H. Schmidt, M. Krug, and V. Höllt. 1997. Design of a multiple slice interface chamber and application for resolving the temporal pattern of CREB phosphorylation in hippocampal long-term potentiation. J. Neurosci. Methods 78: 173-179.

McLean, J.H. and M.T. Shipley. 1991. Postnatal development of the noradrenergic projection from locus coeruleus to the olfactory bulb in the rat. J. Comp. Neurol. 304: 467-477.

McLean, J.H., M.T. Shipley, W.T. Nickell, G. Aston-Jones, and C.K. Reyher. 1989. Chemoanatomical organization of the noradrenergic input from locus coeruleus to the olfactory bulb of the adult rat. J. Comp. Neurol. 285: 339-349.

McLean, J.H., A. Darby-King, R.M. Sullivan, and S.R. King. 1993. Serotonergic influence on olfactory learning in the neonate rat. Behav. Neural Biol. 60: 152-162.

McLean, J.H., A. Darby-King, and G. Paterno. 1995. Localization of $5-\mathrm{HT}_{2 \mathrm{~A}}$ receptor mRNA by in situ hybridization in the olfactory bulb of the postnatal rat. $J$. Comp. Neurol. 353: 371-378.

McLean, J.H., A. Darby-King, and E. Hodge. 1996. 5-HT 2 receptor involvement in conditioned olfactory learning in the neonate rat pup. Behav. Neurosci. 110: 1426-1434.

Michael, D., K.C. Martin, R. Seger, M.M. Ning, R. Baston, and E.R. Kandel. 1998. Repeated pulses of serotonin required for long-term facilitation activate mitogen-activated protein kinase in sensory neurons of Aplysia. Proc. Natl. Acad. Sci. 95: 1864-1869.

Moore, A.N., M.N. Waxham, and P.K. Dash. 1996. Neuronal activity increases the phosphorylation of the transcription factor CAMP response element-binding protein (CREB) in rat hippocampus and cortex. J. Biol. Chem. 271: 14214-14220.

Morin, D., R. Sapena, R. Zini, and J.-P. Tillement. 1992. Serotonin enhances the $\beta$-adrenergic response in rat brain cortical slices. Eur. J. Pharmacol. 225: 273-274.

Nakamura, S., K. Fumitaka, and T. Sakaguchi. 1987. Postnatal development of electrical activity in the locus ceruleus. J. Neurophysiol. 58: 510-524.

Nigg, E.A., H. Hilz, H.M. Eppenberger, and F. Dutly. 1985. Rapid and reversible translocation of the catalytic subunit of cAMP-dependent protein kinase type II from the Golgi complex to the nucleus. EMBO J. 4: 2801-2806.

Price, T.L., A. Darby-King, C.W. Harley, and J.H. McLean. 1998. Serotonin plays a permissive role in conditioned olfactory learning induced by norepinephrine in the neonate rat. Behav. Neurosci. 112: 1430-1437.

Rovescalli, A.C., N. Brunello, J. Perez, S. Vitali, L. Steardo, and G. Racagni. 1993. Heterologous sensitization of adenylate cyclase activity by serotonin in the rat cerebral cortex. Eur. Neuropsychopharmacol. 3: 463-475.

Sakaguchi, H., K. Wada, M. Maekawa, T. Watsuji, and M. Hagiwara. 1999. Song-induced phosphorylation of cAMP response element-binding protein in the songbird brain. J. Neurosci. 19: 3973-3981.

Schwab, M.E. 1996. Structural plasticity of the adult CNS. Negative control by neurite growth inhibitory signals. Int. J. Dev. Neurosci. 14: 379-385.

Silva, A.J., J.H. Kogan, P.W. Frankland, and S. Kida. 1998. CREB and memory. Annu. Rev. Neurosci. 21: 127-148.

Sullivan, R.M. and W.G. Hall. 1988. Reinforcers in infancy: Classical conditioning using stroking or intra-oral infusions of milk as UCS. Dev. Psychobiol. 21: 215-223.

Sullivan, R.M. and M. Leon. 1986a. Early olfactory learning induces an enhanced olfactory bulb response in young rats. Dev. Brain Res. 27: 278-282.

1986b. Early olfactory learning induces an enhanced olfactory bulb response in young rats. Brain Res. 392: 278-282.

1987. One-trial olfactory learning enhances olfactory bulb responses to an appetitive conditioned odor in 7-day-old rats. Dev. Brain Res. 35: 307-311.

Sullivan, R.M., D.A. Wilson, and M.H. Kim. 1988. Behavioral and neural correlates of postnatal olfactory conditioning: I. Effect of respiration on conditioned neural responses. Physiol. Behav. 44: 85-90.

Sullivan, R.M., D.A. Wilson, and M. Leon. 1989a. Norepinephrine and learning-induced plasticity in infant rat olfactory sytem. J. Neurosci. 9: 3998-4006.

1989b. Associative processes in early olfactory preference acquisition: Neural and behavioral consequences. Psychobiology 17: 29-33.

Sullivan, R.M., D.A. Wilson, R. Wong, A. Correa, and M. Leon. 1990. Modified behavioral and olfactory bulb responses to maternal odors in preweaning rats. Dev. Brain Res. 53: 243-247.

Sullivan, R.M., J.L. McGaugh, and M. Leon. 1991. Norepinephrine-induced plasticity and one-trial olfactory learning in neonatal rats. Dev. Brain Res. 60: 219-228.

Tao, X., S. Finkbeiner, D.B. Arnold, A.J. Shaywitz, and M.E. Greenberg. 1998. $\mathrm{Ca}^{2+}$ influx regulates BDNF transcription by a CREB family transcription factor-dependent mechanism. Neuron 20: 709-726.

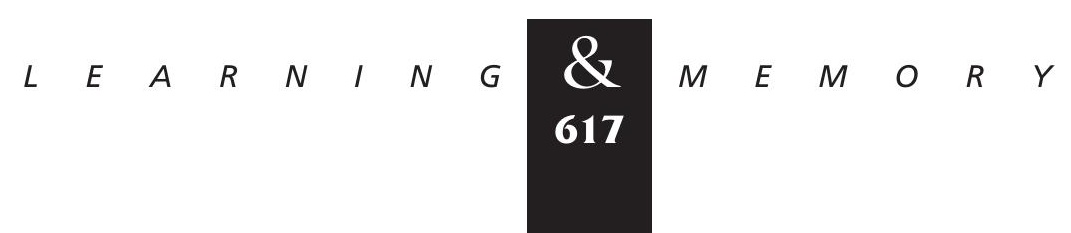




\section{McLean et al.}

Tully, T. 1996. Discovery of genes involved with learning and memory: An experimental synthesis of Hirschian and Benzerian perspectives. Proc. Natl. Acad. Sci.

93: 13460-13467.

Tully, T., T. Preat, S.C. Boynton, and M. Del Vecchio. 1994. Genetic dissection of consolidated memory in Drosophila. Cell 79: 35-47.

Wilson, D.A. and R.M. Sullivan. 1990. Olfactory associative conditioning in infant rats with brain stimulation as reward. I. Neurobehavioral consequences. Dev. Brain Res.

53: $215-221$.

1991. Olfactory associative conditioning in infant rats with brain stimulation as reward: II. Norepinephrine mediates a specific component of the bulb response to reward. Behav. Neurosci. 105: 843-849.

Woo, C.C. and M. Leon. 1987. Sensitive period for neural and behavioral response development to learned odors. Dev. Brain Res. 36: 309-313.

1991. Increase in a focal population of juxtaglomerular cells in the olfactory bulb associated with early learning. J. Comp. Neurol. 305: 49-56.

1995a. Distribution and development of $\beta$-adrenergic receptors in the rat olfactory bulb. J. Comp. Neurol. 352: $1-10$.

1995b. Early olfactory enrichment and deprivation both decrease $\beta$-adrenergic receptor density in the main olfactory bulb of the rat. J. Comp. Neurol. 360: 634-642.

Woo, C.C., R. Coopersmith, and M. Leon. 1987. Localized changes in olfactory bulb morphology associated with early olfactory learning. J. Comp. Neurol. 263: 113-125.

Woo, C.C., D.A. Wilson, R.M. Sullivan, and M. Leon. 1996. Early locus coeruleus lesions increase the density of beta-adrenergic receptors in the main olfactory bulb of rats. Int. J. Dev. Neurosci. 14: 913-919.

Yin, J.C., M. Del Vecchio, H. Zhou, and T. Tully. 1995. CREB as a memory modulator: Induced expression of a dCREB2 activator isoform enhances long-term memory in Drosophila. Cell 81: 107-115.

Received September 18, 1999; accepted in revised form October 15, 1999. 


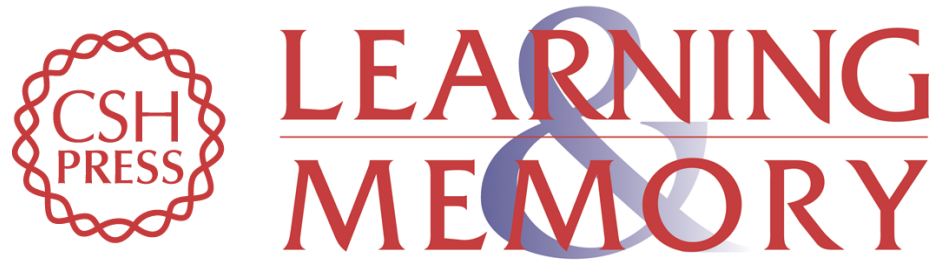

\section{pCREB in the Neonate Rat Olfactory Bulb Is Selectively and Transiently Increased by Odor Preference-Conditioned Training}

John H. McLean, Carolyn W. Harley, Andrea Darby-King, et al.

Learn. Mem. 1999, 6:

Access the most recent version at doi:10.1101//m.6.6.608

References This article cites 60 articles, 10 of which can be accessed free at:

http://learnmem.cshlp.org/content/6/6/608.full.html\#ref-list-1

License

Email Alerting Receive free email alerts when new articles cite this article - sign up in the box at the Service top right corner of the article or click here. 